\title{
Article
}

\section{Comparison of the Properties of Activated Carbons Produced in a One-Stage and a Two-Stage Process}

\author{
Davide Bergna ${ }^{1,2}$, Toni Varila ${ }^{1,2}$, Henrik Romar ${ }^{1}$ and Ulla Lassi ${ }^{1,2}$ \\ 1 University of Oulu, Research Unit of Sustainable Chemistry, P.O. Box 3000, FI-90014 University of Oulu, \\ Finland \\ 2 Kokkola University Consortium Chydenius, University of Jyvaskyla, Unit of Applied Chemistry, \\ Talonpojankatu 2B, FI-67100 Kokkola, Finland
}

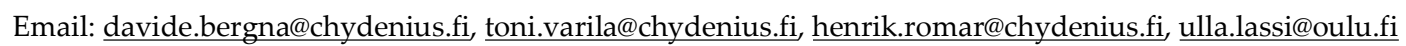

\begin{abstract}
Activated carbons can be produced from biomass in a thermal process either in a direct carbonization-activation process or by first carbonizing the biomass and later on activating the biochars into activated carbons. The properties of the ACs are dependent on the type of process used for production. In this study, the properties of activated carbons produced in a one-stage and a twostage process are considered. Activated carbons were produced by physical activation of two types of starting materials, bio chars produced from spruce and birch chips in a commercial carbonization plant and from the corresponding raw chips. The activated carbons produced were characterized regarding specific surfaces, pore volumes and pore size distributions. The un-activated bio chars had some degree of surface area 190 and $140 \mathrm{~m}^{2} \mathrm{~g}^{-1}$ for spruce and birch and pore volumes of 0.067 and 0.092 $\mathrm{cm}^{3} \mathrm{~g}^{-1}$. According to the results obtained, two slightly different types of activated carbons are produced depending if a one-stage or a two-stage carbonization and activation process is used. The ACs produced in the one-stage process had higher specific surface areas compared to the ones produced in a two-stage process $\left(761-940 \mathrm{~m}^{2} \mathrm{~g}^{-1} \mathrm{vs} .540-650 \mathrm{~m}^{2} \mathrm{~g}^{-1}\right)$. In addition, total pore volumes were higher in one-stage process but development of micropores is greater compared to two-stage process. There was no significant difference in total carbon content between one-stage and two-stage process.
\end{abstract}

Keywords: biomass; bio-char; activation; activated carbon; thermal treatment, physical activation; porosity, specific surface areas

\section{Introduction}

Activated carbons are produced by thermal treatment or a combination of chemical and thermal treatment of carbon-rich sources like lignite or in the case of biomass based carbon from lignocellulosic materials. Typical bio-based raw materials used in the production are coconut shells, peat and wood chips or saw dust [1,2]. Most of the raw materials used in the production of bio-chars and activated carbons can be considered as waste fractions from industrial or agricultural production [3-6]. According to Tadda et al. [3] a number of properties are most important if a feedstock is to be used as source in the production of bio-chars and especially for activated carbons, som eof these properties are presented in Table 1.

Table 1 Properties needed on biomasses to be used as feedstock for production of bio-chars and activated carbons (modified from [3])

\footnotetext{
A high content of carbon

A low content of inorganic ash forming components

Potential extent for activation
} 
Low degradation on storage

High density and sufficient volatile content

Stability in supply in the producing country

Inexpensive materials

The biomasses used in the present study, spruce and birch, fullfil the criteria presented in Table 1, especially in the Nordic countries if waste fractions of wood like thinnings and residues from wood harvesting are used.

In the production process, the organic material is first carbonized at temperatures of $673-973 \mathrm{~K}$, in this process most of the volatile components are released as pyrolysis gases in combination with the breakdown products from cellulose, hemicellulose and lignin, as pyrolytic oil [7]. The product from the carbonization stage is a solid with high carbon content, typically in the range of $25-50 \%$ calculated on a mass basis, depending on the starting material and the process parameters used. The production and activation processes used for the production of bio-chars are described in the review paper of Thompson et al. and in the paper by Wang et al. [8,9]. According to the paper of Thompson bio-chars can to some extent replace activated carbons as adsorbents. The bio-chars produced from agricultural waste are also proposed to be novel precursors in the production of activated carbons [10]

In the second stage with physical activation, the carbons are activated to activated carbons using temperatures in the range of 973 - $1173 \mathrm{~K}$ in combination with activating agents, in the physical activation gases like water (steam) or carbon dioxide $\left(\mathrm{CO}_{2}\right)$ are used as activators. Steam activation has an effect on the specific surface areas, pore volumes and pore size distributions and might increase the O-content [9]. A number of factors are affecting the properties of activated carbonsproduced by physical activation, among them the biomass used, activation time and activation temperature used [3].

From economical point of view, the simplicity and rather low cost are the best advantages of physical activation. On the other hand, low yields are usually obtained using physical activation $[11,12]$. This can be an issue in industrial scale up processes. Reason behind this, lies in the carbonization and activation processes. Parameters, like activation time and temperature has a major impact on the yield. Higher temperature and longer activation time reduces the total yield. This can be explained with a simple matter, at higher carbonization temperatures more volatile compounds are exiting from the system, which leads to lower yield of activated carbon. Furthermore, the activation time effects the yield of activated carbon by partially burning the carbon away because of the oxygen present in steam. The longer the activation period is, the more time steam has to burn the organic compounds, which leads to low yields but rather high specific surface areas and pore volumes. [13-15]

An alternative activating method to produce activated carbons is chemical activation. In chemical activation, chemical agents, e.g., zinc chloride $\left(\mathrm{ZnCl}_{2}\right), \mathrm{KOH}$, $\mathrm{NaOH}$, and $\mathrm{H}_{3} \mathrm{PO}_{4}$, can be used for activating carbon $[11,12,16,17]$. The procedure 
is rather simple, solutions containing the chemical activation agent is impregnated to the surface of biomass, dried in an oven and finally activated in the furnace at 673 to $873 \mathrm{~K}$ for 1 to 4 hours under an inert atmosphere (nitrogen atmosphere). After the activation, the chemical activation agent is refluxed away with diluted mineral acid, filtered and finally dried in an oven.

From the mechanical point of view, chemical reactions that occur during the carbonization process are not well known. Only few studies can be found from the literature about how the chemical activation occurs during the activation. LilloRódenas et al. described the chemical reactions between carbon and alkaline metals $(\mathrm{NaOH}$ and $\mathrm{KOH})$. According to them, the reactions produces metal, hydrogen and metal carbonates. The following reaction can be described with equations 1 and 2 [12].

$$
\begin{aligned}
& 6 \mathrm{NaOH}+2 \mathrm{C} \leftrightarrow 2 \mathrm{Na}+3 \mathrm{H}_{2}+2 \mathrm{Na}_{2} \mathrm{CO}_{3} \\
& 6 \mathrm{KOH}+2 \mathrm{C} \leftrightarrow 2 \mathrm{~K}+3 \mathrm{H}_{2}+2 \mathrm{Na}_{2} \mathrm{CO}_{3}
\end{aligned}
$$

Compared to physical activation, the main advantages of using chemical activation method are higher final carbon yields, the fact that procedure can be done in a one step process, generally lower activation temperatures are required, and an easier adjustment of porosity [11,18-20]. The main disadvantages of using chemical compounds are that they are not environmentally friendly substances and are corrosive towards the equipment used during research. An acid washing step is also needed in order to remove the chemical activating agent [11,21,22].

The carbonization and the activation stages can be performed in two different ways, in a two-stage process where the carbonization and activation stages are separated in time or in a one-stage process where carbonization and activation is performed sequentially in the same reactor. In the two-stage process the starting material is carbonized and the carbon formed is later on activated into activated carbons while the one-stage-process produces activated carbons as the only solid [23].

Characteristic properties for the activated carbons are high carbon content, high specific surface areas and a high level of porosity. The porous structures is divided according to the diameters of the pores into micro pores with a diameter $<2 \mathrm{~nm}$, meso pores with diameters in the size of $2-50 \mathrm{~nm}$ and macro pores with diameters $>50 \mathrm{~nm}$. The distribution of these pores, in combination with the specific surface area is dependent on the starting materials and the process parameters used [23-25]. According to our (so far unpublished) results the specific surface areas and the pore size distribution is highly dependent on the process used for the production.

In the present study we present the results from a screening of the effects of using two different appproaches in the production of activated carbons by physical activation. The study was performed in order to investigate the effects of different processes on the properties of the carbons. Two types of processes are used in the production of activated carbons. As starting materials in both cases are wooden chips 
from spruce and birch. In one process the chips are carbonized and carbons formed are later on activated by steam activation, in this process the carbonization and activation steps are separated in time and space. In the other process the same chips are carbonized and activated in simultaneous one-stage sequence. The activated carbons prepared are characterized with respect to total yields, carbon contents, specific surface areas and pore size distributions and are compared with respect to the process used.The novelty of this study indicates that the ACs porosity can be influenced by the process sequence and not only from the process parameters and the starting material pretreatments.

\section{Materials and Methods}

Biomass used

In the research two types of biomass were used, chips from spruce and birch were carbonized at Carbofex carbonization plant in Tampere, Finland. The carbons were dried in an oven, milled in a ceramic ball mill and sieved to particle sizes less than 2 $\mathrm{mm}$ and finally steam activated for 2 and 4 hours. Wooden chips of spruce and birch were dried, milled and sieved to particle sizes less than $2 \mathrm{~mm}$. The sieved woods were carbonized and steam activated in a one-stage process using activation times of 2 and 4 hours.

About 10 grams of each sample were placed into a fixed-bed steel reactor inserted into a tubular oven. The samples inside the reactor were supported on both sides by quartz wool. For the carbon samples the temperature of the oven was raised from roomtemperature to $1023 \mathrm{~K}$ in a 30 minute period followed by a slow ramp of $6 \mathrm{~K} \mathrm{~min}^{-1}$ to $1073 \mathrm{~K}$. For the wood samples a 120 minutes ramp from room temperature to $1073 \mathrm{~K}$ was applied. At $1073 \mathrm{~K}$ the samples were steam activated by feeding water into the reactor at a speed of $30 \mathrm{~cm}^{3}$ hour-1 for 2 or 4 hours. The reactor was flushed with an inert gas, nitrogen, during the whole process in order to avoid oxidation of the samples. The carbons produced were characterized by a number of methods including yield, total carbon content (TC), specific surface areas and pore size distributions. The samples were named according to Table 1.

Table 2 Naming of the samples used (2/4 indicates activation times used, 2 or 4 hours)

\begin{tabular}{ll}
\hline Sample & Name \\
\hline Raw spruce chips & Spruce untreated \\
Raw birch chips & Birch untreated \\
Carbonized spruce & C spruce \\
Carbonized birch & C birch \\
Carbonized and activated birch (1 stage) & C Birch act $2 / 4$ hours \\
Carbonized and activated spruce (1 stage) & C Spruce act $2 / 4$ hours \\
Activated carbonized spruce & Spruce $2 / 4$ hours \\
Activated carbonized birch & Birch $2 / 4$ hours \\
\hline
\end{tabular}




\section{Calculation of yields}

The yield for each sample was calculated as:

Yield $=$ mass of carbon $/$ mass of feed $* 100$

For the pre-carbonized samples the total yield was calculated

Total yield $=$ yield from activation $*$ yield from carbonization process.

According to the producer of the carbons the yield from carbonization is $30 \%$ calculated on a dry mass basis.

\section{Total carbon}

The percentage of total carbon present in each sample, was measured using Skalar Primacs MCS instrument. Dried samples were weighted in quartz crucibles, combusted at $1373 \mathrm{~K}$ in a pure oxygen atmosphere and the formed $\mathrm{CO}_{2}$ was analyzed by an IR analyzer. Carbon content values were obtained by reading the signal of IR analyzer from a calibration curve derived from known masses of a standard substance, citric acid. The total mass of carbon in each sample was calculated as a percent of the mass initially weighted. With the instrumental method used the presicion of the measurements is in the range of $5 \%$.

\section{Surface areas and pore size distributions}

Specific surface area and pore distributions were determined from the adsorptiondesorption isotherms using nitrogen as adsorbate. Determinations were performed with Micromeritics ASAP 2020 instrument. Portions of each sample (100-200 mg) were degassed at low pressure $(2 \mu \mathrm{m} \mathrm{Hg})$ and at temperature of $413 \mathrm{~K}$ for two hours in order to clean the surfaces and remove any gas adsorbed. Adsorption isotherms were obtained by immersing sample tubes in liquid nitrogen $(77.15 \mathrm{~K})$ to achieve constant temperature conditions. Gaseous nitrogen was added to the samples in small doses and the resulting isotherms were obtained. Specific surface areas and total pore volumes were calculated from adsorption isotherms according to the BET method [26] while the pore size distribution was calculated using the DFT (Density Functional Theory) [27] algorithm assuming slit-formed pores [28]. Total pore volumes were in the BET calculated at a $\mathrm{P} / \mathrm{P}_{0}$ ratio of 0.985 and in the case of the DTF calulation as the total volumes of pores. The $\%$ distribution of pore volumes was calculated from the indivual volumes of $\mu$ pores, mesopores and macropores. With the instrumental setup used, micropores down to $1.5 \mathrm{~nm}$ in diameter could be measured even if there might be some contribution from smaller pores. $\mu$ pore areas and volumes were calculated by the $\mathrm{t}$ plot algoritm and the surafe areas at low $\mathrm{P} / \mathrm{P}_{0}$ ratios were calculated as Langmuir surface areas. According to previous works the SSAs are mesured with a precision of $\pm 5 \%$ [29]. 


\section{Results and discussion}

Yields from the activation and carbonization-activation processes

According to the results presented in Table 2 it appears that the total yields are higher for the two-stage process compared to the one-stage process. The precarbonization leads to rather high yields for the activation step because most of the volatile fractions have been removed in the carbonization but the total yields are at the same level for both procedures. An exact value for the yield in an industrial production of biochar is hard to get but $30 \%$ was used as a mean value declared by the carbon supplier. As expected longer steam activations lead to lower yields, this is more obvious for the one-stage process than the two-stage process. As expected, the total carbon content, in both raw materials, raised from initial $47 \%$ to $95 \%$ during the carbonization process. Despite the one-stage or two-stage process, physical activation with steam reduces the total carbon content in both cases. Approximately 5-10\% lower values were obtained for the spruce based sample depending on the length of the activation time. In the case of birch based samples, only 1-2\% lower carbon contents were obtained. Lower carbon values can be explained with the use of steam in the activation process. Steam partially oxidizes the carbon, creating the porous structure during the activation resulting in a higher ash content but a lower carbon content. 
Table 3 Yields for the activation process. Total yield includes pre-carbonization and activation and are calculated using a $30 \%$ yield in the industrial carbonization stage. Total carbon content for raw materials, carbonized and activated spruce and birch samples.

\begin{tabular}{llll}
\hline Sample & $\begin{array}{l}\text { Total carbon content } \\
(\%)\end{array}$ & $\begin{array}{l}\text { Yield } \\
(\%)\end{array}$ & $\begin{array}{l}\text { Total yield } \\
(\%)\end{array}$ \\
\hline Birch untreated & 47.2 & - & - \\
Birch carbonized & 94.8 & - & - \\
C birch 2h act & 97.1 & 62.6 & 18.8 \\
C birch 4h act & 87.3 & 43.9 & 13.2 \\
Birch 2 h act & 89.7 & - & 10.4 \\
Birch 4 h act & 87.4 & - & 5.5 \\
Spruce untreated & 47.0 & - & - \\
Spruce carbonized & 96.8 & - & - \\
C spruce 2 h act & 96.0 & 56.0 & 16.8 \\
C spruce 4 h act & 94.6 & 38.7 & 11.6 \\
Spruce 2 h act & 99.8 & - & 15.2 \\
Spruce $4 \mathrm{~h}$ act & 95.0 & - & 11.5 \\
\hline
\end{tabular}

Adsorption isotherms, specific surface areas pore volumes and pore size distributions

The two first columns in Table 3 represent the dried, milled and sieved chips of spruce and birch. Results show a very low specific surface areas and the corresponding pore volumes are close to or lower than measuring limit of the method. For the raw materials no porosity could be observed. The un-activated bio chars proved to have some porosity and a specific surface area of 140 (spruce) and $180 \mathrm{~m}^{2} \mathrm{~g}^{-1}$ (birch). The morphology of the pores indicated mainly $\mu$ pores.

According to the results presented in Table 3 there are differences regarding the specific surface areas for the ACs produced in a one-stage process and the ones produced in a two-stage process. All ACs produced in the two-stage process are lower in specific surface areas compared to the ones produced in a one-stage process, the difference is independent on the activation times used even if longer activation times in general produces higher specific surface-areas.

The difference in surface areas is even more pronounced using the Langmuir surfaces where surface areas are in the range of $600-950 \mathrm{~m}^{2} \mathrm{~g}^{-1}$ for the ACs produced in a two stage process compared to surface areas of $900-1200 \mathrm{~m}^{2} \mathrm{~g}^{-1}$ for the ACs produced in the one stage process.

Apparently there is no significant difference in the pore volumes of the ACs calculated from BET while the pore volumes calculated according to DFT are slightly higher for the ACs from the one-stage process. Pore volumes of micropores calculated using the t-plot algoritm are lower for the ACs produced in a one-stage process compared to the ones prepared in a two-stage process.

The external surface areas (t-plot calculations) are higher for the ACs produced in the one stage process. For samples, made in two-stage process, the external surface areas are in the range of $200-370 \mathrm{~m}^{2} \mathrm{~g}^{-1}$ and for samples, made in one-stage process, the external surface areas are in the range of $380-500 \mathrm{~m}^{2} \mathrm{~g}^{-1}$. This can indicate a higer occurance of mesopores for the ACs produced in the two-stage process while the ACs from the one-stage has a pore structure with more micropores. This observation is 
confirmed with the pore size distributions calculated with the DFT function and from the shapes of the isotherms presented in Figure 1. Pore volumes in the samples carbonizedonly without activation were low and most of them are in the micro-pore region.

\section{Adsorption isotherms}

The adsorption isotherms for the carbonized starting materials, two-stage and onstage activated spruce and birch are presented in Figure 1 A-C. There appears to be some difference in the shapes for the adsorbtion isotherms for the samples prepared in a one-stage and two-stage process Figure $1 \mathrm{~A}$ ) and B). This is most likely a result of the difference in pore size distributions as presented in Table 3. In particular, Type I and Type II shape isotherms can be noticed between the AC prepared with different starting materials. The one-stage prepared activated carbon follows a Type I isotherm indicating a more microporous carbon while the two-stage AC presents a Type II adsoprtion isotherm more typical of mesoporous material. The raw carbon shows a Type I isotherm with lower level of volume adsorbed. These results are coeherent with the DFT model as presented in Table 4 where it is evident a high microporosity of the carbonized biomass but a higher mesoporosity in the two-stages prepared activated carbon (about 10\% more).
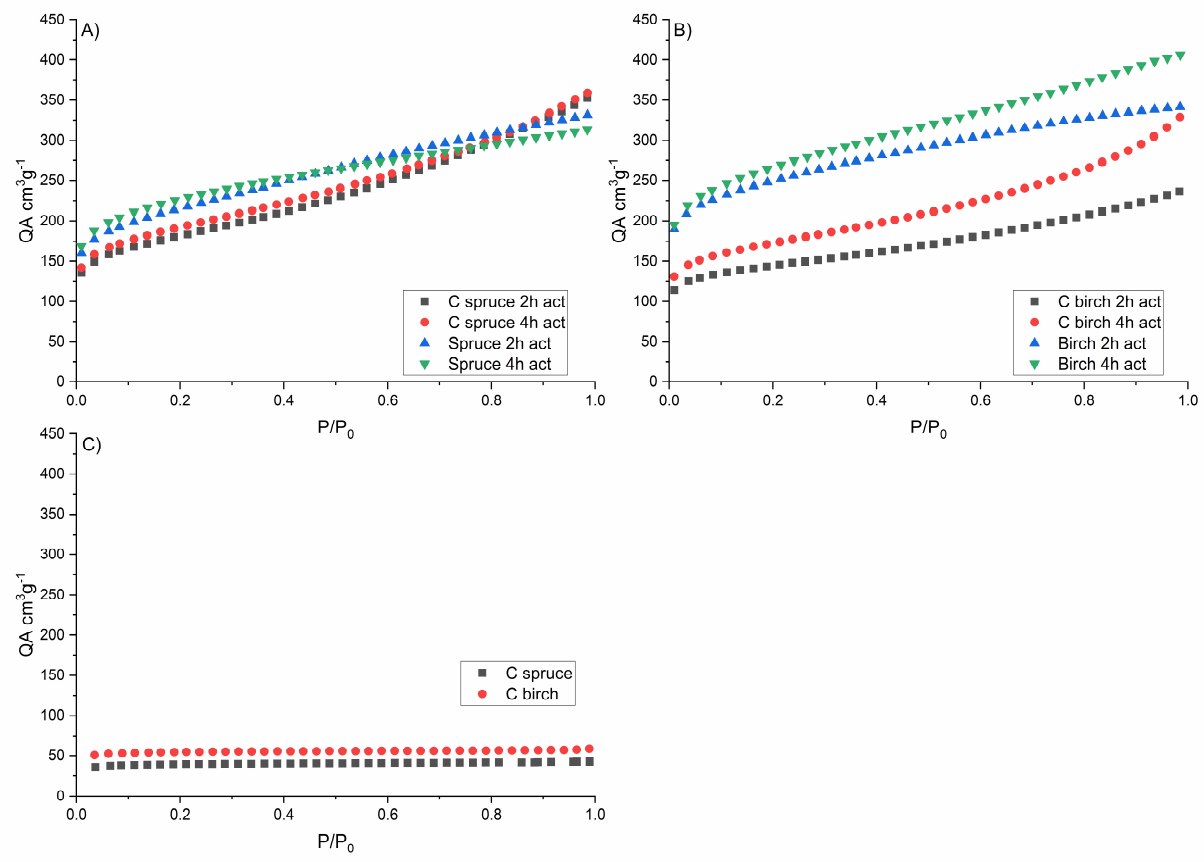

Figure 1 Adsorption isotherms of A) spruce one-stage and two stage activated, B) birch one-stage and two stage activated and C) spruce and birch carbonized only 
In Table 4 it is also evident from the t-Plot model that a predominant part of the surface area of the one-stage produced activated carbon derives from micropores region with the holding time with steam increasing the mesoporosity as known. So it seems that not only the process parameters but also the sequence in activation has an impact in the AC porosity.

The results from the present study confirms our, so far unpublished, observations regarding activation of biochars and wood chips (saw dust) into ACs. According to the results, activated carbons produced in a one-stage and a two-stage process have different properties regarding specific surface areas, pore volumes and pore size distributions. The reasons for the differences is so far speculations only but can possibly be found in the carbonization reactions and the breakdown of the structures building up the wood.

Additionally, contact with air might change the properties of the surface of the biochars making them less sensitive to the activating agent. In the industrial production of the biochars a continuous process is used while the laboratory tests were performed in a fixed bed reactor in batch mode; the process parameters used might affect the properties of the ACs produced. Similar, so far unpublished, results have previously been obtained using biochars produced in batch mode indicating that there are structural effects in the biochars rather than the production process itself that makes the differences.

Further tests using chemical activation with different activating agents could be performed to find out if the differences are related to the properties of the precursors used, to the activating process itself or to the activating agent. 
Peer-reviewed version available at C 2018, 4, 41; doi:10.3390/c4030041

Table 4 Specific surface areas and pore-size distributions for the starting materials, carbonized biochars and the activated carbons.

\begin{tabular}{|c|c|c|c|c|c|c|c|c|c|c|c|c|c|}
\hline $\begin{array}{l}\text { Calculation } \\
\text { method }\end{array}$ & Unit & $\begin{array}{l}\text { Birch } \\
\text { untreated }\end{array}$ & $\begin{array}{l}\text { Spruce } \\
\text { untreated }\end{array}$ & C birch & C spruce & $\begin{array}{l}\mathrm{C} \text { birch } \\
2 \mathrm{~h} \text { act }\end{array}$ & $\begin{array}{l}\text { C birch } \\
4 \text { h act }\end{array}$ & $\begin{array}{l}\text { C spruce } \\
2 \mathrm{~h} \text { act }\end{array}$ & $\begin{array}{l}\text { C spruce } \\
4 \mathrm{~h} \text { act }\end{array}$ & $\begin{array}{l}\text { Birch } \\
2 \mathrm{~h} \text { act }\end{array}$ & $\begin{array}{l}\text { Birch } \\
4 \mathrm{~h} \text { act }\end{array}$ & $\begin{array}{l}\text { Spruce } \\
2 \mathrm{~h} \text { act }\end{array}$ & $\begin{array}{l}\text { Spruce } \\
4 \mathrm{~h} \text { act }\end{array}$ \\
\hline \multicolumn{14}{|l|}{ BET } \\
\hline SSA & $\mathrm{m}^{2} \mathrm{~g}^{-1}$ & 0.6 & 0.4 & 190 & 140 & 530 & 617 & 647 & 679 & 761 & 814 & 910 & 943 \\
\hline Pore volume & $\mathrm{cm}^{3} \mathrm{~g}^{-1}$ & 0.002 & * & 0.091 & 0.067 & 0.366 & 0.509 & 0.545 & 0.555 & 0.513 & 0.484 & 0.528 & 0.628 \\
\hline $\begin{array}{l}\text { Langmuir surface } \\
\text { area } \\
\text { t-plot }\end{array}$ & $\mathrm{m}^{2} \mathrm{~g}^{-1}$ & 1.0 & 0.3 & 240 & 173 & 653 & 732 & 766 & 812 & 910 & 985 & 1140 & 1180 \\
\hline micropore volume & $\mathrm{cm}^{3} \mathrm{~g}^{-1}$ & * & * & 0.074 & 0.053 & 0.132 & 0.136 & 0.128 & 0.136 & 0.151 & 0.18 & 0.204 & 0.195 \\
\hline micropore area & $m^{2} g^{-1}$ & * & * & 167 & 123 & 322 & 318 & 303 & 317 & 344 & 425 & 495 & 447 \\
\hline $\begin{array}{l}\text { External surface } \\
\text { area }\end{array}$ & $\mathrm{m}^{2} \mathrm{~g}^{-1}$ & * & * & 23 & 18 & 208 & 300 & 348 & 369 & 417 & 388 & 416 & 496 \\
\hline \multicolumn{14}{|l|}{ DFT } \\
\hline pore volume & $\mathrm{cm}^{3} \mathrm{~g}^{-1}$ & * & * & 0.075 & 0.054 & 0.29 & 0.38 & 0.433 & 0.446 & 0.427 & 0.401 & 0.446 & 0.527 \\
\hline upores & $\mathrm{cm}^{3} \mathrm{~g}^{-1}$ & * & * & 0.071 & 0.051 & 0.15 & 0.167 & 0.168 & 0.183 & 0.216 & 0.242 & 0.268 & 0.274 \\
\hline Mesopores & $\mathrm{cm}^{3} \mathrm{~g}^{-1}$ & * & * & 0.004 & 0.003 & 0.14 & 0.213 & 0.265 & 0.263 & 0.211 & 0.159 & 0.178 & 0.253 \\
\hline Macropores & $\mathrm{cm}^{3} \mathrm{~g}^{-1}$ & * & * & 0.001 & 0.001 & 0 & 0 & 0 & 0 & 0 & 0 & 0 & 0 \\
\hline upores & $\%$ & * & * & $94 \%$ & $94 \%$ & $52 \%$ & $44 \%$ & $39 \%$ & $41 \%$ & $51 \%$ & $60 \%$ & $60 \%$ & $52 \%$ \\
\hline Mesopores & $\%$ & * & * & $5.3 \%$ & $5.0 \%$ & $48 \%$ & $56 \%$ & $61 \%$ & $59 \%$ & $49 \%$ & $40 \%$ & $40 \%$ & $48 \%$ \\
\hline Macropores & $\%$ & * & * & $1.3 \%$ & $1.2 \%$ & $0 \%$ & $0 \%$ & $0 \%$ & $0 \%$ & $0 \%$ & $0 \%$ & $0 \%$ & $0 \%$ \\
\hline
\end{tabular}

$*=$ indicates that values were too low to be measured 


\section{Conclusions}

It is well known that biomass biomass used for the carbonization and activation in the production of activated carbons is one of the most important factors regarding the properties of the product. In this study a comparison between two different routes in the production of ACs for activating carbon has been performed. The results presented gives some new understanding of the parameters influencing the production of ACs with different properties.

According to the results, there are some differences in the properties of ACs produced depending on if the biomass is directly carbonized and activated or first carbonized and the resulting biochar is later on activated. Regarding the total carbon content in the ACs produced there is no significant difference between the processes. The yield is apparently higher using the two-stage process. ACs with higher surface areas are produced in the one-stage carbon activation process. The total pore volume of one-stage process results to be in general higher while the pore distribution presents a particular difference as evidenced by the adsorption isotherms t-Plot and DFT model.

\section{Acknowledgments}

The study was supported of and performed within the projects Renepro (20200224) funded by Interreg Nord $(\mathrm{HR})$ and BothniaBioraff (TV). Economical support was received from the Central Ostrobothnia Cultural Foundation (DB).

\section{Author Contributions}

Davide Bergna performed some of the carbonization and activation tests, analyzed the results from the BET tests, performed and analyzed the TC tests and wrote part of the manuscript. Toni Varila performed sample pretreatments, some carbonizations and activations, performed BET measurements, analyzed TC results and wrote parts of the manuscript. Henrik Romar planned the design of the experiments, performed most of the BET measurements, analyzed results and wrote part of the manuscript. Ulla Lassi Planning of research, responsible leader of this research project (and research group), supervisor of $\mathrm{PhD}$ theses of Bergna and Varila and one contributor to the manuscript.

\section{Conflicts of Interest}

The authors declare no conflict of interest. 


\section{Reference List}

[1] M. Ahmedna, W.E. Marshall, R.M. Rao, Bioresour. Technol. 71 (2000) 113-123.

[2] M.J. Antal, M. Grønli, Ind. Eng. Chem. Res. 42 (2003) 1619-1640.

[3] M.A. Tadda, A. Ahsan, A. Shitu, M. ElSergany, T. Arunkumar, B. Jose, Abdur Razzaque, M., N.N. Nik Daud, Journal of Advanced Civil Engineering Practice and Research. 2(1) (2016) 7-13.

[4] M.A. Mohammed, A. Shitu, M.A. Tadda, M. Ngabura, International Research Journal of Environment Sciences. 3(3) (2014) 67-71.

[5] M.R. Snowdon, A.K. Amar K. Mohanty, M. Misra, ACS Sustainable Chemistry \& Engineering. 2 (2014) 1257.

[6] D. Bergna, H. Romar, S. Tuomikoski, H. Runtti, T. Kangas, P. Tynjälä, U. Lassi, in: L. Singh, V.C. Kalia (Eds.), Waste Biomass Management - A Holistic Approach, Springer, 2017, pp. 187-213.

[7] M.J. Antal, M. Gronli, Ind. Eng. Chem. Res. 42 (2003) 1619-1640.

[8] K.T. Thompson, K.K. Shimabuku, J.P. Kearns, D.R.U. Knappe, R.S. Summers, S.M. Cook, Environ. Sci. Technol. 50 (2016) 11253-11262.

[9] B. Wang, B. Gaob, J. Fang, Critical Reviews in Environmental Science and Technology. (2018) 1-50.

[10] M.A. Yahya, Z. Al-Qodah, C.W.Z. Ngah, Renewable and Sustainable Energy Reviews. 46 (2015) 218235.

[11] S. Yorgun, N. Vural, H. Demiral, Microporous and Mesoporous Materials. 122(1) (2009) 189-194.

[12] M.A. Lillo-Rodenas, D. Cazorla-Amoros, A. Linares-Solano, Carbon. 41 (2003) 267-275.

[13] A. Baçaoui, A. Yaacoubi, A. Dahbi, C. Bennouna, R.P.T. Luu, F.J. Maldonado-Hodar, J. Rivera-Utrilla, C. Moreno-Castilla, Carbon. 39(3 (2001) 425-432.

[14] A.C. Lua, T. Yang, J. Colloid Interf. Sci. 274(2) (2004) 594-601.

[15] K. Yang, J. Peng, C. Srinivasakannan, Zhang, L., Xia, H., X. Duan, Bioresource Technology. 101(15) (2010) 6163-6169.

[16] A. Mohammad-Khah, R. Ansari, International Journal of ChemTech Research. 1 (2009) 859-864.

[17] T. Varila, D. Bergna, R. Lahti, H. Romar, T. Hu, U. Lassi, Bioresources. 12(4) (2017) 8078-8092.

[18] J. Hayashi, A. Watkinson, K. Teo, S. Takemoto, K. Muroyama, 8th International Conference on Coal Science, Oviedo, Spain. (1995) 1121-1124.

[19] A. Ahmadpour, D.D. Do, Carbon. 34 (1996) 471-479.

[20] H. Benaddi, D. Legras, J. Rouzaud, F. Beguin, Carbon. 36(3) (1998) 306-309.

[21] H. Teng, H.-. Lin, AICHE J. 44(5) (1998) 1170-1177.

[22] S. Yorgun, D. Yıldız, Journal of the Taiwan Institute of Chemical Engineers. 53 (2015) 122-131.

[23] Ö Şahin, C. Saka, Bioresour. Technol. 136 (2013) 163-168.

[24] K. Yang, J. Peng, H. Xia, L. Zhang, C. Srinivasakannan, S. Guo, Journal of the Taiwan Institute of Chemical Engineers. 41 (2010) 367-372.

[25] A.A. Ceyhan, Ö Şahin, O. Baytar, C. Saka, J. Anal. Appl. Pyrolysis. 104 (2013) 378-383.

[26] S. Brunauer, P.H. Emmett, E. Teller, Journal of the American Chemical Society. Volume 60 (1938) 309.

[27] W. Seaton, A. Quirke, Carbon. 27(6) (1989) 876-861.

[28] C. Lastoskie, K.E. Gubbins, N. Quirke, Langmuire. 9 (1993) 2693-2702.

[29] V.A. Hackley, A.B. Stefaniak, Journal of Nanoparticle Research. 15:1742 (2013) 1--8. 